\title{
Trabalhonecessário
}

Memória e Documentos

\section{PROJETO RONDON: RELAÇÕES ENTRE UNIVERSIDADE E SOCIEDADE}

Francisco José da Silveira Lobo Neto²

\section{I- Breve contextualização histórica dos documentos (1966-2019)}

Há três fases no Projeto Rondon. A primeira da origem, em 1966, até 1985 com a extinção da Fundação Projeto Rondon. Assim o Projeto permaneceu em hibernação até 2003, quando a União Nacional dos Estudantes faz ao Presidente Lula o pedido de retomada das operações do Projeto. A formação de um grupo de trabalho em 2004 e o Decreto de 14 de janeiro de 2005 que cria o Comitê de Orientação e Supervisão do Projeto Rondon, representa bem uma segunda fase.

A grande questão é se o Decreto n. 9.848, de 25 de junho de 2019, cria uma nova fase, a terceira, ou não. Creio que ainda não temos elementos concretos para responder a esta questão, porque as operações deflagradas em 2019, foram orientadas e planejadas em 2018.

O I Seminário sobre Educação e Segurança Nacional, aberto na Escola de Estado-Maior do Exército - ECEME no Rio de Janeiro, em 17 de outubro de 1966, foi o berço da ideia que, posteriormente, se concretizou como o Projeto Rondon. (cfr. Correio da Manhã, edição de 22 de outubro de 1966, p. 2).

\footnotetext{
${ }^{1}$ Texto recebido em 25/07/2020. Aprovado pelos editores em 16/08/2020. Publicado em 25/09/2020. DOI: https://doi.org/10.22409/tn.v18i37.44596

${ }^{2}$ Doutor em Educação pela Faculdade de Educação da Universidade Federal Fluminense - UFF, Niterói (RJ), Professor Aposentado de História da Educação da UFF, Professor-Pesquisador do Laboratório de Trabalho e Educação Profissional em Saúde (LATEPS) da Escola Politécnica de Saúde Joaquim Venâncio (EPSJV) da Fundação Oswaldo Cruz (Fiocruz) - Rio de Janeiro, Brasil. Email::sloboneto@gmail.com ORCID: 0000-0002-9292-3069.

Lattes: http://lattes.cnpq.br/2774154084956899
} 
Neste Seminário é que o Professor Wilson Choeri, diretor do Departamento Cultural e Vice-Reitor da Universidade do Estado da Guanabara - UEG (hoje Universidade do Estado do Rio de Janeiro - UERJ), apresenta a ideia do que seria futuramente o Projeto Rondon, inspirado na experiência da Universidade Volante do Paraná "de onde retirou conhecimentos operacionais fundamentais" (GURGEL ROCHA, 1986, p. 116).

A Comissão Diretora foi formada pelo Diretor do Departamento Nacional de Educação; Reitores das Universidades; representantes do Estado Maior das Forças Armadas - EMFA; do Conselho de Segurança Nacional - CSN; do Ministério das Relações Exteriores - MRE; e o comandante da ECEME, Coronel Mattos Júnior, que a presidia. (cfr. CORREIO DA MANHÃ, idem).

Formaram-se cinco Comissões Temáticas:

a) Principais setores e formas da contribuição da Universidade à Segurança Nacional;

b) Intercâmbio entre as faculdades e as academias militares;

c) Intercâmbio de órgãos civis e militares de ensino secundário;

d) Visualização da contribuição das Forças Armadas na Educação para a cidadania;

e) Exequibilidade da criação de um órgão de coleta de dados e informações de natureza cultural.

Estas Comissões entregaram seus relatórios conclusivos nas plenárias de $7 \mathrm{e}$ 11 de novembro seguintes. Participaram do Seminário, representantes de entidades da Presidência da República; do Ministério da Educação e Cultura (MEC); da Universidade Federal do Rio de Janeiro - UFRJ; da Pontifícia Universidade Católica PUC-Rio; da Universidade do Estado da Guanabara - UEG; do Colégio de aplicação da Faculdade Nacional de Filosofia - FNFi; de várias Associações; dos Ministérios da Aeronáutica, da Marinha e do Exército. Este Seminário preocupava-se com uma aproximação entre civis e militares, depois do fato que partes deles se uniram para perpetrar a ruptura da Constituição de 1946 em um golpe, auto definido como 'Revolução'. Ele - como o próprio nome "Educação e Segurança Nacional" e o tema da primeira Comissão indicam - preocupa-se com a doutrina fundamental da Escola Superior de Guerra, isto é a Doutrina da Segurança Nacional. Todas as áreas 
abrangidas pelas Comissões submetem-se ao sistema conceitual e estratégico desta doutrina, sempre relacionada ao desenvolvimento nacional.

Quanto ao pensamento político dos militares brasileiros, segundo afirma Rodrigo Lentz (2019, p. 44), ele foi constituído com fundamentos das doutrinas positivistas e nacionalistas "com postulados segurança e desenvolvimento aliados ao anticomunismo". Desenvolveu-se na doutrina de segurança nacional do Estado Novo. E depois foi adaptada, no pós-guerra (Guerra Fria), pela ESG (criada em 1949). mesmo Lentz (idem, p. 68-69) sintetiza "a ideologia nacional dos militares brasileiros" nos seguintes termos:

- Crença 1 - atributos brasileiros - Individualismo, Adaptabilidade, Improvisação, $\quad$ Pacifismo, Cordialidade, Emotividade; $\cdot$ Crença 2 - cristianismo transcendental - A crença em Deus a partir do cristianismo, e nas consequentes leis eterna e natural, condicionam verticalmente o pensamento como um todo. Especialmente com a noção de "bem comum" nos termos do cristianismo; •Crença 3 - liberalismo conservador - a verdadeira essência democrática seria aquela desenhada pela sequência "amor- justiça-pazliberdade-progresso" do positivismo e, no caso brasileiro, as instituições políticas seriam, por ordem histórico-cultural inspiradas nos modelos francês (cultura), inglês (instituições) e estadunidense (república federativa). Essa concepção é resumida na ideia do Brasil destinado a ser uma grande potência; •Crença 4 anticomunismo - o comunismo é o inimigo-objetivo da doutrina, apontado como o grande conjunto de valores, ideias e crenças antagônicas à doutrina, devido a sua concepção de luta entre as classes sociais, ateísmo, materialismo histórico e visão negativa das instituições políticas, em especial o Estado;•Crença 5 neocapitalismo - rejeição ao Estado empresário em favor de um Estado ajustador do capitalismo, especialmente na funçãoconsumo, resumidos pelos conceitos de ética do sucesso, individualismo, expansão do poder das grandes empresas e racionalpassionalismo dos consumidores.

E considera "que ter clareza da herança autoritária no pensamento político dos militares brasileiros é uma chave de interpretação fundamental do presente" (ibidem, p.69).

Nada mais previsto do que se originar neste Seminário, no contexto das Comissões, uma proposta síntese de enviar universitários às comunidades mais carentes, para exercitar nelas as profissões em que se estavam formando. Neste sentido, as Universidades e Faculdades estariam colaborando com a segurança nacional pela integração dos jovens às realidades longínquas; havia uma 
aproximação entre civis e militares, além de fortalecer o intercâmbio das instituições militares e civis.

Oito meses depois do encerramento do Seminário, a denominada "Operação Zero" se deflagrou. Trinta estudantes e dois professores de universidades do Estado da Guanabara (o professor da UEG, Omar Fontoura, coordenava o grupo), partiram para Rondônia, à época território federal. Lá ficaram, por 28 dias, conhecendo "de perto a realidade amazônica", através de levantamentos e pesquisa, bem como promover cuidados de saúde e auxiliar o desenvolvimento de projetos para a população local.

\section{Imagem 1- 1967 - “Operação Zero”}

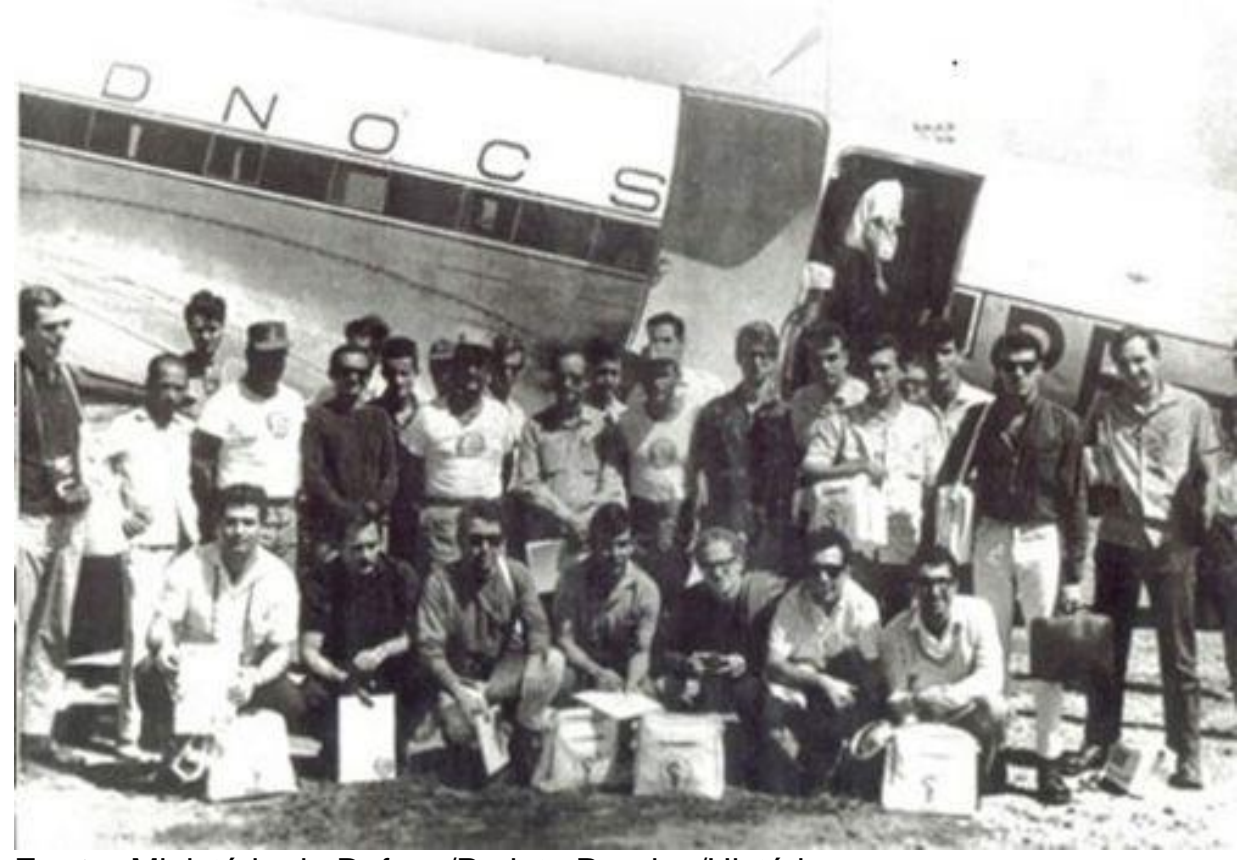

Fonte: Ministério da Defesa/Projeto Rondon/Histórico

Os próprios estudantes, ao regressarem de Rondônia, "propuseram a criação de um movimento universitário que desse prosseguimento ao trabalho iniciado no território visitado" (cfr. PROJETO RONDON, s/d). E os voluntários da chamada "Operação Zero" denominaram seu movimento de Projeto Rondon, em homenagem ao Marechal Cândido Mariano da Silva Rondon", que construiu "mais de 4,5 mil

\footnotetext{
${ }^{3}$ Cândido Mariano da Silva Rondon (1865-1958) entrou na Escola Militar do Rio de Janeiro aos 16 anos, tendo se destacado como militar do Exército Brasileiro, não só pela integração por linhas telegráficas, mas como desbravador do sertão e pacificador dos índios. Em 1910 foi o primeiro Diretor do Serviço
} 
quilômetros de linhas telegráficas" na Amazônia, unindo na comunicação a Região Norte a Centro-Oeste, "ajudando a ocupar a região do atual Estado de Rondônia ... fez contatos com várias tribos indígenas, tratando-as pacificamente" (GONÇALVES, 2017, p.7-8).

Segundo o Correio da Manhã de 10 de janeiro de 1968, os vinte um sextanista da Faculdade de Medicina da UEG (pertencentes ao Grupo Marinhan-1) já estavam percorrendo na Região Amazônica "as populações ribeirinhas" nas corvetas Mearim e Solimões, providenciando "atendimento médico", assim como "cursos rápidos de higiene, primeiros socorros e educação sanitária". Cinquenta e oito estudantes do Sul estavam sendo esperados, no dia 15 de janeiro, para o Estado do Amazonas e ainda iriam os integrantes do Grupo Roraima. O "movimento universitário", com apoio do Ministério do Interior, Ministério da Educação e Cultura e Forças Armadas, cinco meses antes de formalizado o Decreto presidencial 62.927, de 28 de junho de 1968, foi a campo interagir com as populações carentes da Amazônia.

Este Decreto cria, "em caráter permanente, um Grupo de Trabalho (GT), denominado 'Projeto Rondon' diretamente subordinado ao Ministério do Interior” com o objetivo de promover estágios para estudantes universitários conduzindo "a juventude a participar do processo de integração nacional” (BRASIL, 1968).

Esse GT converte-se em Fundação Projeto Rondon pela Lei n. 6.310, de 15 de dezembro de $1975^{4}$. Continua vinculada ao Ministério do Interior e terá a finalidade de "motivar a participação voluntária da juventude estudantil no processo do Desenvolvimento, da Integração Nacional e da Valorização do Homem, em cooperação com o Ministério da Educação e Cultura”. (BRASIL, 1975, Art. $1^{\circ}, \S 1^{\circ}$ ).

Em janeiro de 1989, através da Medida Provisória n. 28/1989, que o Congresso Nacional converte na Lei n. 7.732, de 14 de fevereiro de 1989 (BRASIL,1989), José Sarney resolve extinguir autarquias federais e fundações públicas, entre elas, a Fundação Projeto Rondon. A Associação Nacional dos Rondonistas criada como Organização Não Governamental em 1990, depois reconhecida como Organização

de Proteção aos Índios. Ao pacificar tribos antropófagas, ordenava aos seus subordinados que seguissem o lema "Morrer, se preciso for, matar nunca". Em 1952, viu aprovado seu projeto do "Parque Nacional do Xingu". A Câmara dos Deputados, em 1955, concedeu-lhe as insígnias de Marechal. Em 1956, o território de Guaporé, recebeu em sua homenagem o nome de Rondônia. Faleceu em 1958.

${ }^{4}$ Neste mesmo ano, a Universidade Federal Fluminense - UFF, que vinha desenvolvendo ações no Estado do Pará desde 1972, transfere definitivamente seu Campus para Oriximiná.

(cfr. http://www.uff.br/?q=cidade/oriximina-pa Acesso em julho de 2020). 
da Sociedade Civil de Interesse Público (OSCIP) pelo Ministério da Justiça, manteve "vivo o idealismo de seus pioneiros". No rastro da Associação Nacional, criaram-se similares, independentes, nas Unidades Federadas (cfr. GONÇALVES, 2017, p. 17).

Em novembro de 2003, a União Nacional dos Estudantes encaminhou ao Presidente da República, Luiz Inácio Lula da Silva, a retomada oficial do Projeto Rondon. Criou-se um grupo de trabalho interministerial, em março de 2004, cujos membros eram representantes do Ministério da Defesa (que devia coordenar o GT e a segunda fase do Projeto Rondon), do Ministério da Educação, do Ministério da Integração Nacional, do Ministério da Saúde, do Ministério do Desenvolvimento Agrário, do Ministério do Desenvolvimento Social, do Ministério do Esporte, do Ministério do Meio Ambiente e da Secretaria Geral da Presidência da República.

Em 14 de janeiro de 2005, um Decreto Presidencial "cria o Comitê de Orientação e Supervisão do Projeto Rondon", sendo seu Presidente o representante do Ministério da Defesa ${ }^{5}$, a quem cabe "prover o apoio administrativo e os meios necessários à execução dos trabalhos do Comitê". O Decreto tem um Anexo em que são elencadas as "Diretrizes Básicas para a Execução das Ações do Projeto Rondon" (cfr. BRASIL, 2005).

Na cidade de Tabatinga (AM), o Presidente Lula, no dia 19 de janeiro de 2005, lançou a primeira operação da nova fase do Projeto Rondon afirmando ser o momento de "unir brasileiros de todas as origens e de todas as regiões" na retomada de uma "política de integração e desenvolvimento regional" (UOL NOTíCIAS, 2005).

O I Congresso Nacional do Projeto Rondon, realizou-se somente em 2013, em Ribeirão Preto (SP). Paralelamente ao I Congresso, reuniu-se o I Fórum Nacional dos Estudantes Rondonistas e VII Reunião dos Professores. Fruto do Congresso foi a Carta de São Paulo, reivindicando que o Projeto Rondon, seja um Programa de Estado e solicitando aos políticos uma lei que o torne permanente (cfr. AZEVEDO et al., 2014). Talvez tenham esquecido da Lei da criação da Fundação Projeto Rondon, que foi revogada pela Medida Provisória n.28/1985, extinguindo-a, e o Projeto também.

O Decreto de 14 de janeiro de 2005 foi revogado pelo Presidente Jair Messias Bolsonaro, em nova reformulação do Comitê de Orientação e Supervisão do Projeto Rondon, dada pelo Decreto n. 9.848, de 25 de junho de 2019.

${ }^{5}$ O Vice-Presidente, José Alencar Gomes da Silva, acumulava as funções de Ministro da Defesa. 
$\mathrm{Na}$ atual configuração, o Comitê passa a ser definido como "órgão de assessoramento" - o que diminui concretamente sua força de decisão - e as diretrizes passam para o Art. 3ํ do corpo do Decreto, excetuando a de "assegurar a participação da população na formulação e no controle das ações". O que significa esta eliminação? Certamente, a não explicitação da população "na formulação e controle das ações" pode significar a exclusão da população local, em dizer o que espera e em exercer um controle sobre as ações. Assim, de nove diretrizes no Anexo do Decreto anterior, passam a ser oito diretrizes.

\section{II- Os Documentos: Decretos, Leis sobre a trajetória do Projeto Rondon}

1- Decreto n. 62.927 de 28 de junho de 1968.

Institui, em caráter permanente, o Grupo de Trabalho "Projeto Rondon", e dá outras providências.

O PRESIDENTE DA REPÚBLICA, no uso das atribuições que lhe confere o Art. 83, item II da Constituição,

\section{DECRETA:}

Art. 1․ Fica instituído em caráter permanente, um Grupo de Trabalho, denominado "Projeto Rondon" com sede na cidade do Rio de Janeiro, diretamente subordinado ao Ministério do Interior, com a finalidade de promover estágios de serviço para estudantes universitários, objetivando conduzir a juventude a participar do processo de integração nacional.

Parágrafo único. O Grupo de Trabalho poderá coordenar suas atividades com quaisquer outras da mesma natureza que se realizem no país.

Art. 2․ O Grupo de Trabalho, ao qual caberá a organização de planos e projetos específicos, será constituído por um representante dos seguintes órgãos:

a) Ministério do Interior;

b) Ministério da Educação e Cultura;

c) Ministério da Marinha;

d) Ministério do Exército;

e) Ministério da Aeronáutica;

f) Ministério dos Transportes; 
g) Ministério da Agricultura;

h) Ministério do Planejamento e Coordenação Geral;

i) Ministério da Saúde;

j) Movimento Universitário de Desenvolvimento Econômico e Social - MUDES;

k) Conselho de Reitores, representando as entidades de ensino superior.

Parágrafo único. Integrará, ainda, o Grupo de Trabalho um representante da Universidade do Estado da Guanabara - UEG, em face de sua participação pioneira no

Projeto.

Art. 3․ Os trabalhos do Grupo ora criado serão desenvolvidos com apoio básico em um Núcleo Central, constituído pelos representantes do Ministério do Interior, do Ministério da Educação e Cultura, do Ministério da Marinha, do Ministério do Exército, do Ministério da Aeronáutica e do Conselho de Reitores.

Parágrafo único. Ao Núcleo Central compete orientar, coordenar e prover o apoio às atividades do "Projeto Rondon" e deliberar sobre conclusões, sugestões ou providências a serem adotadas.

Art. 4․ Os estágios de serviço a que se refere o artigo 1ํㅡㄹ serão realizados durante o período de férias escolares, obedecendo aos objetivos e ao plano geral de trabalho constantes de instruções que serão baixadas pelo Núcleo Central.

Art. 5․ . G Grupo de Trabalho e seu Núcleo Central serão presididos por um Coordenador Geral, de livre escolha do Ministro de Estado do Interior.

Parágrafo único. O Núcleo Central do Grupo de Trabalho reunir-se-á por convocação do Coordenador Geral, na sede do Ministério do Interior, ou em local diverso por ele indicado.

Art. 6․ O Coordenador Geral responsável direto perante o Ministério do Interior, promoverá, sempre que julgar necessário aos objetivos do "Projeto Rondon" e ocorrer motivação no meio universitário, a criação de Grupos ou Subgrupos Regionais, com atuação em um ou mais Estados ou Territórios.

Parágrafo único. Caberá ao Coordenador Geral a designação dos Coordenadores regionais.

Art. 7ํ․ Os órgãos da Administração Federal, direta ou indireta existentes nas diferentes áreas, darão o necessário apoio aos grupos regionais.

Art. $8^{\circ}$. Continuam em vigor as atuais normas para funcionamento do Grupo de 
Trabalho "Projeto Rondon" devendo, dentro de 90 (noventa) dias, ser elaborado seu Regimento Interno.

Art. 9․ As atividades do "Projeto Rondon" serão custeados com recursos proporcionados pelo Ministério do Interior ou por ele obtidos, e constituídos, de:

a) créditos que lhe forem atribuídos;

b) donativos, subvenções, auxílios contribuições e legados de particulares;

c) contribuição proveniente de acordos e convênios com entidades públicas e privadas;

dotações que foram consignadas nos orçamentos da União, Estados,

d) Municípios, Entidades Paraestatais, Autarquias e Sociedades de Economia Mista;

e) Rendas eventuais.

$\S 1^{\circ}$ Os recursos indicados neste artigo serão depositados em conta especial no Banco do Brasil S.A. e movimentados pelo Coordenador Geral do Grupo de Trabalho.

$\S 2^{\circ}$ A aplicação desses recursos será feita rigorosamente de acordo com o planejamento apresentado pelo Grupo de Trabalho e aprovado pelo Ministro de Estado do Interior, no qual serão discriminados os trabalhos a serem executados, a modalidade de financiamento e os respectivos orçamentos.

Art. 10. Aos participantes do "Projeto Rondon" serão conferidos certificados correspondentes aos serviços prestados; às instituições de Direito Privado e pessoas jurídicas que se destacarem no apoio às atividades do "Projeto Rondon" serão conferidos diplomas ou medalhas.

Art. 11. Poderá ser autorizada a dispensa de ponto, pelo prazo máximo de 30 dias por ano, para os servidores civis dos Ministérios, Autarquias e Sociedades de Economia Mista, aos participantes, universitários, técnicos e professores que integrarem as diferentes operações do "Projeto Rondon".

Art. 12. O presente decreto entrará em vigor na data de sua publicação, revogadas as disposições em contrário.

Brasília, 28 de junho de 1968; 147º da Independência e 80ํ da República.

A. COSTA E SILVA

José Moreira Maia

Aurélio de Lyra Tavares

Mário David Andreazza

Ivo Arzua Pereira

Tarso Dutra

Carlos Alberto Huet de Oliveira Sampaio 
Leonel Miranda

João Paulo dos Reis Velloso

Afonso A. Lima

Este texto não substitui o original publicado no Diário Oficial da União - Seção 1 de 01/07/1968.

2 - Lei n. 6.310, de 15 de dezembro de 1975.

Autoriza a instituição da Fundação Projeto Rondon, e dá outras providências.

\section{O PRESIDENTE DA REPÚBLICA:}

Faço saber que o CONGRESSO NACIONAL decreta e eu sanciono a seguinte Lei:

Art. 1ำ Fica o Poder Executivo autorizado a instituir, com sede e foro na Capital Federal, uma Fundação, com patrimônio próprio e personalidade jurídica de direito privado, nos termos da lei civil, denominada Fundação Projeto Rondon.

$\S 1$ 1․ A Fundação, vinculada ao Ministério do Interior, terá como finalidade motivar a participação voluntária da juventude estudantil no processo do Desenvolvimento, da Integração Nacional e da Valorização do Homem, em cooperação com o Ministério da Educação

e

Cultura.

$\S 2^{\circ}$. Para o atendimento da finalidade estabelecida no parágrafo anterior, a Fundação terá como objetivo:

I - no campo do desenvolvimento e da integração nacional:

a) colaborar com o Ministério da Educação e Cultura na organização, implantação e coordenação de estágios de estudantes, no interior do país;

b) colaborar na execução da política de integração nacional, em consonância com os planos de desenvolvimento;

c) promover ou participar de programas de desenvolvimento comunitário com as populações interioranas.

II - no campo do mercado de trabalho e mão-de-obra: promover, com os estágios de universitários, o conhecimento das condições

a) do interior do país, abrindo perspectivas para a interiorização e fixação de técnicos de nível superior nas áreas em que atuarem;

desenvolver, junto às populações carentes, o treinamento especializado de

b) nível médio, incentivando o mercado de trabalho e o aprimoramento da mãode-obra qualificada; 
c) promover, juntamente com os órgãos especializados, a abertura de novos mercados de trabalho;

d) promover a interiorização de técnicos em áreas menos desenvolvidas do Território Nacional.

III - no campo da pesquisa e preparação de recursos humanos:

a) contribuir para a promoção, coordenação e realização de pesquisas voltadas para o conhecimento da realidade nacional; b) contribuir para a preparação dos recursos humanos necessários ao

$\S 3^{\circ}$. Na execução dos seus programas de desenvolvimento, a Fundação, para as atividades de extensão universitária, atuará em coordenação com o Ministério da Educação e Cultura, principalmente através dos "Campi" Avançados e de outros programas similares, compatibilizando seu funcionamento com as diretrizes básicas estabelecidas

por aquele

Ministério.

Art. $2^{\circ}$ No ato de constituição da Fundação Projeto Rondon, após a aprovação do respectivo Estatuto por decreto do Poder Executivo, o Governo Federal será representado pelo Ministro de Estado do Interior.

Art. 3ํ A Fundação Projeto Rondon gozará de autonomia administrativa, financeira, didática e disciplinar e adquirirá personalidade jurídica a partir da inscrição, no Registro Civil das Pessoas Jurídicas, do seu ato constitutivo, com o qual será apresentado o respectivo Estatuto e o Decreto que o houver aprovado.
Art.4ํㅡㄴ Constituirão
0
patrimônio
da
Fundação:

I- dotações consignadas no Orçamento Geral da União; II- bens doados ou adquiridos pelo Projeto Rondon; III- doações, subvenções, auxílios, contribuições ou legados de pessoas físicas ou jurídicas, de direito público ou de direito privado; IV- contribuições provenientes de acordos com entidades públicas ou privadas, nacionais, estrangeiras e internacionais; $\mathrm{V}$ - rendas ou emolumentos provenientes de serviços prestados a pessoas jurídicas de direito público ou privado; VI- bens oriundos de entidade que, nos termos desta Lei, venham a ser incorporados à

VII - bens da União atualmente em poder do Projeto Rondon;

VIII- outras rendas eventuais.

Parágrafo único. O patrimônio, a renda e os serviços da Fundação gozarão da imunidade prevista na alínea " c ", item III, do artigo 19, da Constituição.

Art. 5ㅇ orçamento da União consignará, em exercício, recursos suficientes ao atendimento das despesas da Fundação. 
Art. 6ํㅗs despesas necessárias à implantação da Fundação correrão à conta dos recursos orçamentários e extraordinários destinados ao Projeto Rondon.

Art. $7^{0}$ Serão órgãos da Fundação, com a constituição e atribuições fixadas no respectivo

Estatuto:
a) Conselho Diretor;
b) Conselho Curador;
c) Presidência.

Art. 8을 Serão extensivos à Fundação os privilégios da Fazenda Pública quanto à impenhorabilidade de bens, rendas e serviços, prazos processuais, ações especiais e executivas juros

e custas.

Art. 9ำ A Tabela Provisória de Lotação de Pessoal do atual Projeto Rondon será considerada extinta, passando seus servidores, a critério da Fundação, a integrar o Quadro de Pessoal da entidade.

$\S 1^{\circ}$. O regime de pessoal da Fundação será o da legislação trabalhista.

$\S 2^{\circ}$. O Quadro e a remuneração de pessoal da Fundação, depois de aprovado por seu Presidente, serão submetidos a homologação do Ministério de Estado do Interior, devendo observar as condições do mercado de trabalho e as diretrizes da política de pessoal do Governo Federal.

Art. 10. A Fundação promoverá, quando conveniente, a incorporação de entidades privadas congêneres, na forma da legislação em vigor, e, quando for o caso, a absorção de atividades cometidas a órgãos da Administração Federal Direta ou Indireta, desde que compatíveis com a finalidade estabelecida no $\S 1^{\circ}$, do artigo $1^{\circ}$, da

presente

Lei.

Parágrafo único. A absorção de atividades atribuídas a órgãos da Administração Federal Direta ou Indireta far-se-á mediante decreto do Poder Executivo.

Art. 11. No prazo de 90 (noventa) dias, a contar da publicação desta Lei, o Ministro de Estado do Interior submeterá à aprovação do Presidente da República o projeto do $\begin{array}{lllll}\text { Estatuto da } & \text { Fundação }\end{array}$

Art. 12. Instituída a Fundação, será considerado extinto o Projeto Rondon.

$\S 1$ ‥ As dotações orçamentárias consignadas à Coordenação do Projeto Rondon no Orçamento da União serão automaticamente transferidas a Fundação, na data de sua instituição.

$\S 2^{\circ}$. Cumprido o disposto no caput deste artigo, ficará extinto o Fundo do Projeto Rondon (FUNRONDON) de que trata o artigo 13 do Decreto no 67.505, de 6 de novembro de 1970, cujos recursos serão automaticamente transferidos à Fundação. 
Art. 13. Esta Lei entrará em vigor na data de sua publicação, revogadas as disposições em contrário.

Brasília, 15 de dezembro de 1975; 154º da Independência e 87º da República.

ERNESTO GEISEL

Ney Braga

João Paulo dos Reis Velloso

Maurício Rangel Reis

Este texto não substitui o original publicado no Diário Oficial da União - Seção 1 de $16 / 12 / 1975$

3 - Decreto de 14 de janeiro de 2005

Cria o Comitê de Orientação e Supervisão do Projeto Rondon e dá outras providências

O PRESIDENTE DA REPÚBLICA, no uso da atribuição que the confere o art. 84, inciso VI, alínea "a", da Constituição,

\section{DECRETA:}

Art. 1ำ Fica criado o Comitê de Orientação e Supervisão do Projeto Rondon, que terá por objetivos:

1 - executar as ações do Projeto Rondon de acordo com as diretrizes básicas constantes do Anexo a este Decreto;

II - orientar a política de atuação do Projeto Rondon; e

III - propor diretrizes para as atividades a serem desenvolvidas.

Art. 2o O Comitê será integrado por um representante, titular e suplente, de cada órgão a seguir indicado:

I - Ministério da Defesa, que o presidirá;

II - Ministério da Educação;

III - Ministério do Desenvolvimento Social e Combate àFome;

IV - Ministério da Saúde;

$V$ - Ministério do Meio Ambiente;

VI - Ministério da Integração Nacional;

VII - Ministério do Esporte;

VIII - Ministério do Desenvolvimento Agrário; e

IX - Secretaria-Geral da Presidência da República. 
$\S 1^{\circ}$ Os membros do Comitê serão indicados pelo titular do órgão representado e designados pelo Ministro de Estado da Defesa.

$\S 2^{\circ}$ Os membros do Comitê terão mandato de dois anos, podendo ser reconduzidos.

$\S 3$ 3ㅇ Comitê deliberará mediante resoluções, por maioria simples dos presentes, tendo seu Presidente o voto de qualidade no caso de empate.

Art. 3ํㅇ Comitê contará com as seguintes Comissões:

I - de Coordenação-Geral, com natureza técnica e articuladora, voltada para a implementação das diretrizes emanadas do Comitê e para a direção das atividades desenvolvidas no âmbito do Projeto Rondon;

II - de Coordenação Operacional e Administrativa, com natureza executiva, voltada para a confecção do plano operacional anual e de sua execução; e

III - de Coordenação Regional, com natureza executiva, ativada conforme as necessidades e a dimensão dos trabalhos nas regiões de atuação.

Parágrafo único. Poderão ser convidados a participar das Comissões personalidades e representantes de outros órgãos e de entidades públicas e privadas.

Art. 4ํㅗ̃o atribuições do Presidente do Comitê:

I - convocar e presidir as reuniões do colegiado;

II - solicitar a elaboração de estudos, informações e posicionamento sobre temas de relevante interesse público na área de sua atuação;

III - firmar atas das reuniões e homologar as resoluções; e

IV - constituir e organizar as Comissões.

Art. 5ㅇ $\mathrm{O}$ regimento interno do Comitê será submetido pelo seu Presidente à aprovação do colegiado e disporá sobre a organização, a forma de apreciação e a deliberação das matérias, bem como sobre o funcionamento das Comissões.

Art. 60 Caberá ao Ministério da Defesa prover o apoio administrativo e os meios necessários à execução dos trabalhos do Comitê e das Comissões.

Art. $7^{\circ}$ As atividades dos integrantes dos membros do Comitê e das Comissões são consideradas serviço público relevante, não remuneradas.

Art. 8ํㅡㄹ Este Decreto entra em vigor na data de sua publicação.

Brasília, 14 de janeiro de 2005; 184ํㅡㄹ da Independência e 117º da República. 
José Alencar Gomes da Silva

Este texto não substitui o publicado no D.O.U. de 17.1.2005

\section{A NEXO RONDON \\ DIRETRIZES BÁSICAS PARA A EXECUÇÃO DAS AÇÕES DO PROJETO}

Viabilizar a participação do estudante universitário nos processos de desenvolvimento e de fortalecimento da cidadania.

Contribuir para o desenvolvimento sustentável nas comunidades carentes, usando as habilidades universitárias.

Estimular a busca de soluções para os problemas sociais da população, formulando políticas públicas locais, participativas e emancipadoras.

Contribuir na formação acadêmica do estudante, proporcionando-lhe o conhecimento da realidade brasileira, o incentivo à sua responsabilidade social e o patriotismo.

Manter articulações com as ações de órgãos e entidades governamentais e nãogovernamentais, em seus diferentes níveis, evitando a pulverização de recursos financeiros e a dispersão de esforços em ações paralelas ou conflitantes.

Assegurar a participação da população na formulação e no controle das ações.

Priorizar áreas que apresentem maiores índices de pobreza e exclusão social, bem como áreas isoladas do território nacional, que necessitem de maior aporte de bens e serviços.

Democratizar o acesso às informações sobre benefícios, serviços, programas e projetos, bem como recursos oferecidos pelo poder público e iniciativa privada e seus critérios de concessão.

Buscar garantir a continuidade das ações desenvolvidas.

4 - Decreto n. 9.848, de 25 de junho de 2019.

Dispõe sobre o Comitê de Orientação e Supervisão do Projeto Rondon.

O PRESIDENTE DA REPÚBLICA, no uso da atribuição que the confere o art. 84, caput, inciso VI, alínea "a", da Constituição, 


\section{DECRETA:}

Art. 1ํㅡste Decreto dispõe sobre o Comitê de Orientação e Supervisão do Projeto Rondon.

Art. $2^{\circ} \mathrm{O}$ Comitê de Orientação e Supervisão é órgão de assessoramento destinado a:

I - propor diretrizes para as ações do Projeto Rondon;

II - detalhar os objetivos e as orientações relativos ao Projeto Rondon; e

III - executar as ações do Projeto Rondon de acordo com as diretrizes estabelecidas no art. 3ํ.

Art. $3^{\circ} \mathrm{A}$ execução das ações do Projeto Rondon observará as seguintes diretrizes:

I - viabilizar a participação do estudante universitário nos processos de desenvolvimento e de fortalecimento da cidadania;

II - contribuir para o desenvolvimento sustentável nas comunidades carentes, com o uso das habilidades universitárias;

III - estimular a busca de soluções para os problemas sociais da população, por meio da formulação e disseminação de políticas públicas locais, participativas e emancipadoras;

IV - contribuir para a formação acadêmica do estudante, a fim de lhe proporcionar o conhecimento da realidade brasileira e incentivar a responsabilidade social e o patriotismo;

$\mathrm{V}$ - manter articulações com as ações de órgãos e entidades governamentais e não-governamentais, em seus diferentes níveis;

VI - priorizar áreas que apresentem maiores índices de pobreza e exclusão social e áreas menos populosas e isoladas do território nacional, que necessitem de maior oferta de bens e serviços;

VII - democratizar o acesso às informações sobre benefícios, serviços, programas e projetos, e os recursos oferecidos pelo Poder Público e pela iniciativa privada e seus critérios de concessão; e

VIII - promover a continuidade das ações desenvolvidas.

Art. 4으 O Comitê de Orientação e Supervisão do Projeto Rondon é composto por representantes dos seguintes órgãos:

I - Ministério da Defesa, que o presidirá;

II - Ministério da Agricultura, Pecuária e Abastecimento; 
III - Ministério da Educação;

IV - Ministério da Cidadania;

V - Ministério da Saúde;

$\mathrm{VI}$ - Ministério do Meio Ambiente;

VII - Ministério do Desenvolvimento Regional; e

VIII - Secretaria de Governo da Presidência da República.

$\S 1^{\circ}$ Cada membro do colegiado terá um suplente, que o substituirá em suas ausências e impedimentos.

$\S 2^{\circ}$ Os membros do Comitê de Orientação e Supervisão do Projeto Rondon e respectivos suplentes serão indicados pelos titulares dos órgãos que representam e designados pelo Ministro de Estado da Defesa.

$\S$ 3ํㅜ Poderão ser convidados a participar dos trabalhos do comitê, sem direito a voto, personalidades e representantes de outros órgãos e de entidades públicas e privadas.

Art. 5o O Comitê de Orientação e Supervisão do Projeto Rondon se reunirá em caráter ordinário duas vezes por semestre e em caráter extraordinário sempre que convocado por seu Presidente.

$\S 1^{\circ} \mathrm{O}$ quórum de reunião do Comitê é de maioria absoluta e o quórum de aprovação é de maioria simples.

$\S 2^{\circ}$ Além do voto ordinário, o Presidente do Comitê de Orientação e Supervisão do Projeto Rondon terá o voto de qualidade em caso de empate.

$\S 3$ 3 Os membros do Comitê de Orientação e Supervisão que se encontrarem no Distrito Federal se reunirão presencialmente e os membros que se encontrem em outros entes federativos participarão da reunião por meio de videoconferência.

Art. 60 O Comitê de Orientação e Supervisão poderá instituir subcolegiados com o objetivo de:

I - avaliar e selecionar as propostas de trabalho das ações do Projeto Rondon;

II - analisar os relatórios das ações; e

III - providenciar os trabalhos técnicos necessários ao funcionamento do Comitê de Orientação e Supervisão do Projeto Rondon.

Art. $7^{\circ}$ Os subcolegiados:

I - serão compostos na forma de ato do Comitê de Orientação e Supervisão do Projeto Rondon;

II - não poderão ter mais de trinta membros;

III - terão caráter temporário e duração não superior a um ano; e 
IV - estão limitados a três operando simultaneamente.

Art. 8ำ A Secretaria-Executiva do Comitê de Orientação e Supervisão será exercida pelo Ministério da Defesa.

Art. 9으 Comitê de Orientação e Supervisão elaborará e aprovará o seu regimento interno.

Art. 10. A participação no Comitê de Orientação e Supervisão e nos subcolegiados será considerada prestação de serviço público relevante, não remunerada.

Art. 11. Fica revogado o Decreto de 14 de janeiro de 2005, que cria o Comitê de Orientação e Supervisão do Projeto Rondon.

Art. 12. Este Decreto entra em vigor na data de sua publicação.

Brasília, 25 de junho de 2019; 198ํ da Independência e 131º da República.

JAIR MESSIAS BOLSONARO

Fernando Azevedo e Silva

Este texto não substitui o publicado no DOU de 26.6.2019

\section{III- Considerações Finais}

Ainda sobre o Projeto Rondon cabem questões que tocam campos interdisciplinares, que vão da História à Ciência Política e à Pedagogia. Neste sentido, selecionamos alguns trabalhos e alguns documentos que se encontram nas Referências.

No corpo da coluna 'Memória e Documentos', apenas os Decretos e Leis, que demonstram a trajetória do Projeto Rondon. Nem foi admitida neste elenco, a Medida Provisória do Presidente Sarney, convertida em Lei pelo Congresso Nacional, extinguindo a Fundação Projeto Rondon, por ser seca e burocrática, não fazendo jus a milhares de estudantes que se voluntariaram para ser rondonistas da primeira fase.

Tanto as Universidades quanto as Faculdades estavam num movimento pré1964 de extensão. O uso da expressão "movimento" é proposital. Antes mesmo de $1911^{6}$, o movimento estudantil empurrava as instituições a levar à sociedade, de forma

\footnotetext{
${ }^{6}$ Ano em que o Decreto n. 8.659, de 5 de abril, aprovava a Lei orgânica do Ensino Superior e Fundamental da República.
} 
pontual e esporádica, os frutos de seu Trabalho em pesquisa e ensino. E é Luciane Pinho de Almeida (2015, p. 6) que nos ensina:

No ano de 1937, com a criação da União Nacional dos Estudantes UNE, intensificaram os protestos e ações do movimento estudantil, retornando com muita força a discussão da proposta da extensão universitária. Mas foi apenas em 1956, que o movimento estudantil passou a adotar postura mais ativa na vida da sociedade brasileira.

Assim, não há que se estranhar que a UNE tenha proposto, ao Presidente Lula, a retomada do Projeto Rondon depois de 15 anos. Na maturidade da extensão universitária, estas ações faziam mais sentido ainda, na medida de que criavam oportunidades de maior número de estudantes circulasse em campi avançados de suas próprias universidades e de outras universidades.

O importante é resgatar critérios essenciais para a democracia, como participação das populações locais na formulação e controle das ações; como uma educação da cidadania como aperfeiçoamento de direitos individuais e sociais, e nenhuma submissão às realidades perversas da desigualdade; como uma segurança nacional que integre e desenvolva sustentavelmente a todos; como igualdade de condições de educação e saúde para todos.

\section{Referências}

ALMEIDA, Luciane Pinho de. A extensão universitária no Brasil: processos de aprendizagem a partir experiência e do sentido. In: Dire, n. 7, 2015. Disponível em https://www.unilim.fr/dire/692. Acesso em julho de 2020.

AZEVEDO et al. I Congresso Nacional do Projeto Rondon. In: Mundo Rondon, v. I, n.1, p.20-23, 2014.

BRASIL. CONGRESSO NACIONAL. Lei n. 6.310, de 15 de dezembro de 1975. Brasília (DF): D.O.U. Seção 1, de 16/12/1975, p. 16.684. Disponível em https://www2.camara.leg.br/legin/fed/lei/1970-1979/lei-6310-15-dezembro-1975366404-publicacaooriginal-1-

pl.htm|\#: :text=1\%C2\%BA\%20Fica\%200\%20Poder\%20Executivo,\%C2\%A7\%201\% C2\%BA. Acesso julho 2020.

. CONGRESSO NACIONAL. Lei n. 7.732, de 14 de fevereiro de 1989.

Brasília (DF): D.O.U. Seção 1, de 15/02/1989. Disponível em http://www.planalto.gov.br/ccivil_03/Leis/L7732.htm\#: :text=LEI\%20No\%207.732\%2 C\%20DE\%2014\%20DE\%20FEVEEREIRO\%20DE\%201989.\&text=Disp\%C3\%B5e\%2 0sobre\%20a\%20extin\%C3\%A7\%C3\%A30\%20de,federais\%20e\%20d\%C3\%A1\%20o utras\%20provid\%C3\%AAncias. Acesso em julho de 2020. 
PRESIDÊNCIA DA REPÚBLICA. Decreto n. $\mathbf{6 2 . 9 2 7}$ de 28 de junho de 1968. Brasília (DF): D.O.U. Seção 1, 01.07.1968, p. 5.387. Disponível em https://www2.camara.leg.br/legin/fed/decret/1960-1969/decreto-62927-28-junho1968-404732-publicacaooriginal-1-pe.html. Acesso em julho 2020.

2005.Brasília (DF): D.O.U. Seção 1, de 17/01 /2005.

Decreto de 14 de janeiro de Decreto n. 9.848, de 25 de junho de 2019. Brasília (DF): D.O.U. Seção 1, de 26/06/2019.

CASTRO, Aline K. A. e GENRO, Maria E.H. A Universidade pública e o Projeto Rondon: espaços de democratização. In: X ANPEd Sul, Florianópolis (SC), 2014.

CAZES, Leonardo Faria. Tempo de reforma, tempo de repressão: a trajetória de Wilson Choeri na Universidade do Estado do Rio de Janeiro. Dissertação Mestrado - Niterói (RJ): Universidade Federal Fluminense, Instituto de História, 2017.

CLEMENTE, Augusto Junior e JULIANO, Maíra Cabral. A Produção do Conhecimento em Cidadania no Brasil: uma análise a partir de Scielo. In: TOMO, n. 23, jul./dez. 2013. Disponível em https://doi.org/10.21669/tomo.v0i23.2109. Acesso em julho de 2020.

CORREIO DA MANHÃ. Militares vêem em Seminário ligação sobre educação. Edição 22562 de 22 de out 1966, p. 2. Rio de Janeiro (RJ). Disponível em http://hemerotecadigital.bn.br/acervo-digital/correio-manha/089842 Acesso em julho 2020.

Jovens-Rondon já ocupam Amazônia. Edição 22934 de 10

de janeiro de 1968, p. 8. Rio de Janeiro (RJ). Disponível em http://hemerotecadigital.bn.br/acervo-digital/correio-manha/089842. Acesso em julho 2020.

GONÇALVES, Daniel E. Projeto Rondon: a Força Aérea Brasileira integrando o Brasil. Rio de Janeiro (RJ): Inst. Hist.-Cult. Aeronáutica, 2017.

GONÇALVES, Nadia G. Doutrina de Segurança Nacional e Desenvolvimento na Ditadura Civil-Militar: estratégias e a educação. In: Anais do XXVI Simpósio Nacional de História. São Paulo (SP), julho 2011. Disponível em http://www.snh2011.anpuh.org/resources/anais/14/1300650153_ARQUIVO_textoanp uh2011ngg.pdf.Acesso em julho 2020.

GONÇALVES, Nadia G. e VIEIRA, Carina S. Extensão Universitária no Período da Ditadura: concepções e relações com a Doutrina de Segurança Nacional e Desenvolvimento. In: ANTÍTESES, v. 8 n. 15, p.269-291. Londrina (PR): UEL, 2015. Disponível em http://www.uel.br/revistas/uel/index.php/antiteses/issue/view/1102/showToc . Acesso em julho 2020.

GURGEL ROCHA, Roberto M. Extensão universitária: comunicação ou domesticação? São Paulo: Cortez, 1986. 
LENTZ, Rodrigo. O Pensamento Político dos Militares Brasileiros: a doutrina de "Segurança Nacional" revisitada (1930-1985). In: Revista da Escola Superior de Guerra, v. 34, n. 70, p. 39-71, jan.-abr. 2019. Disponível em https://revista.esg.br/index.php/revistadaesg/article/view/1059. Acesso em julho de 2020.

PROJETO RONDON. Nossa História. s/d. Disponível em https://projetorondon.defesa.gov.br/portal/index/pagina/id/9718/area/C/module/defaul t . Acesso julho 2020.

UOL NOTÍCIAS. $\quad$ Disponível em https://noticias.uol.com.br/ultnot/reuters/2005/01/19/ult27u46884.jhtm Acesso em julho 2020. 